\title{
PRIMARY RENAL SARCOMA WITH MORPHOLOGIC AND IMMUNOHISTOCHEMICAL ASPECTS COMPATIBLE WITH SYNOVIAL SARCOMA
}

\author{
CARLOS H. SCHAAL, FÁBIO C. NAVARRO, FRANCISCO A. MORAES NETO \\ Amaral Carvalho Hospital, Jaú, São Paulo, Brazil
}

\begin{abstract}
Primary synovial sarcoma of the kidney is a rare tumor that is difficult to diagnose. We present one case that was not diagnosed through fine needle aspiration, requiring a morphologic and immunohistochemical analysis of the incision biopsy. Since the tumor was surgically unresectable, chemotherapy was employed previously to definitive radical surgery.
\end{abstract}

Key words: kidney neoplasms; synovial sarcoma; surgery; chemotherapy

Int Braz J Urol. 2004; 30: 210-3

\section{INTRODUCTION}

The synovial sarcoma is an uncommon tumor, representing approximately 6 to $10 \%$ of the primary sarcomas of soft tissues. Recently, rare primary cases were described in the kidney (1-3). Signs and symptoms are similar to any primary renal tumor. Unspecific preoperative findings, associated with its rarity, prevent its early diagnosis.

\section{CASE REPORT}

Male, 27-year old patient, presenting gross hematuria and large abdominal mass. The abdominal computed tomography showed a large retroperitoneal mass, radiologically consistent with malignant neoplasia (Figure-1). Aspiration puncture of the lesion was performed with fine needle, diagnosing small cell malignant neoplasia (Figure-2).

During staging, no distant lesions were observed. Due to the large tumor volume, an option was made to performing adjuvant chemotherapy. A chemotherapy protocol for Wilms' tumor was started, with actinomycin $50 \mu \mathrm{g} / \mathrm{Kg}$ and vincristine $0.04 \mathrm{mg} /$ $\mathrm{Kg}$, for 4 cycles, obtaining minimal response, with the mass remaining unresectable.

Open biopsy of the lesion was indicated, aiming a better subtyping of the neoplasia. Histopathological examination revealed a malignant neoplasia constituted by 2 distinct cell populations, one consisting of small cells with round hyperchromatic nu-

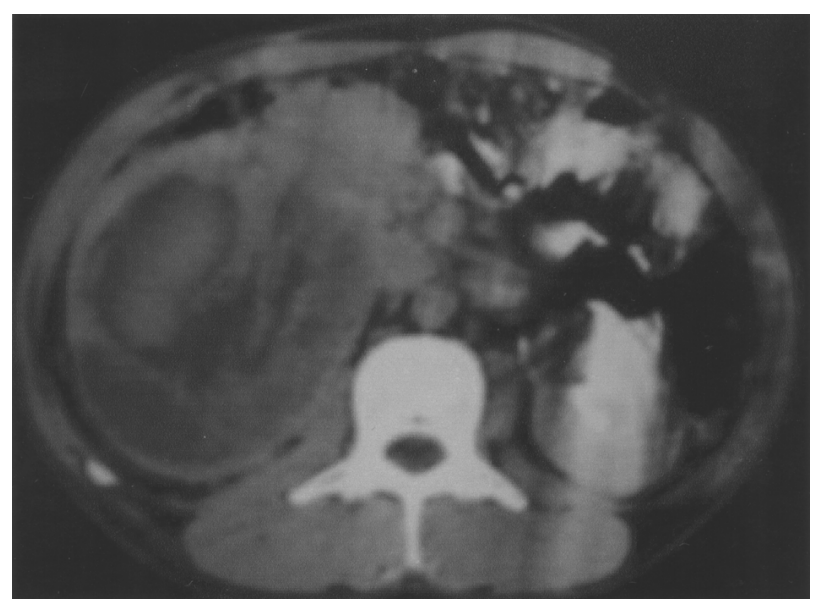

Figure 1 - Abdominal computed tomography evidencing a voluminous tumoral mass in right kidney. 
clei and high mitotic index (poorly differentiated subtype with high malignancy grade) and the other of spindle cells with oval nuclei, fine chromatin, indistinct nucleoli and low mitotic index (monophasic fibrous subtype with low malignancy grade) surrounding renal tubules cystically dilated (Figure-3). The immunohistochemical study was consistent with synovial sarcoma: positive for pan-cytokeratin, epithelial membrane antigen, vimentin, $\mathrm{Bcl}-2$ and negative for CD99/MIC-2, muscle-specific desmin and actin HHF-35 (Figure-4). A new chemotherapy cycle was promptly started with iphosphamide $50 \mathrm{mg} / \mathrm{Kg}$ and adriamycin $1 \mathrm{mg} / \mathrm{Kg}$, for 4 weeks.
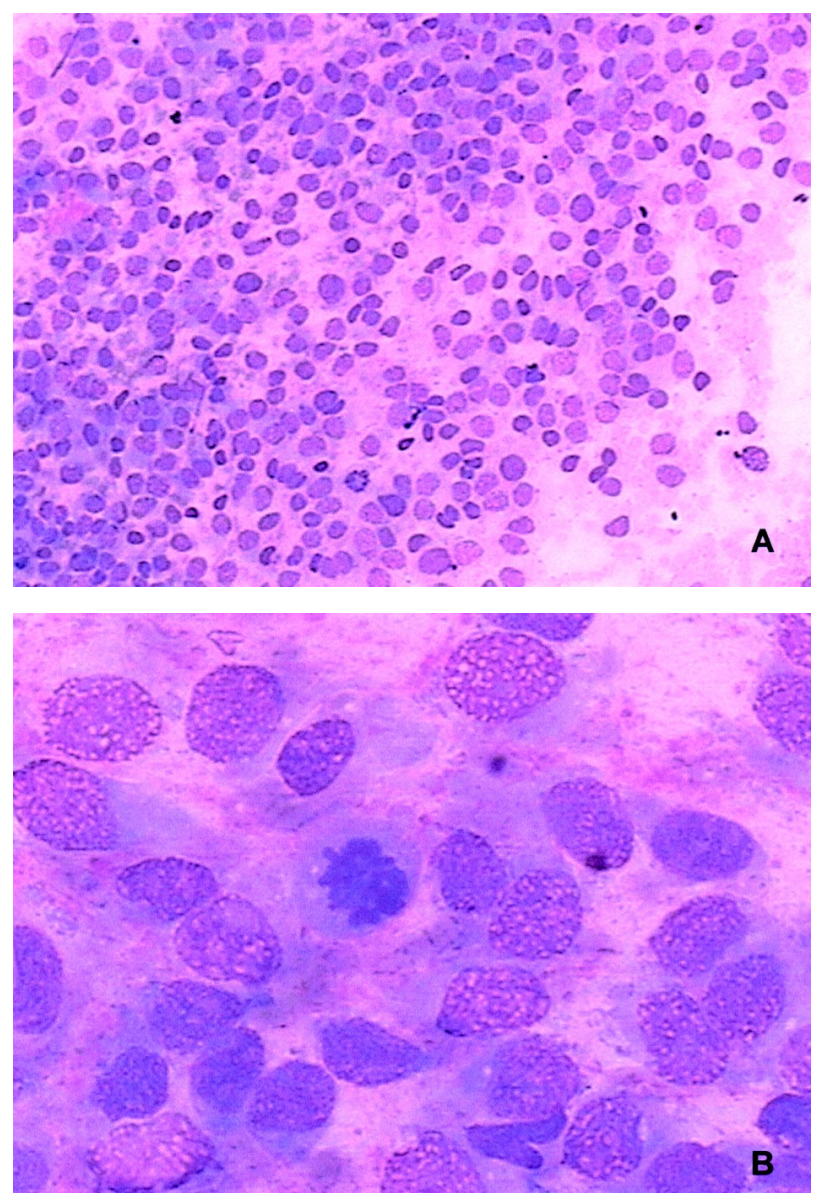

Figure 2 - Smears obtained by fine needle aspiration puncture. A) - Abundant scattered small round cells. B) - Detail of tumor cells with ovoid nuclei, scarce cytoplasm and mitotic figure (Giemsa, X33 and X132, respectively).
With the considerable reduction of the tumor (approximately 50\%), radical nephrectomy by right thoracolaparotomy was indicated, with partial exeresis of diaphragm and ascending colon being necessary. No macroscopically involved lymph nodes were found intraoperatively.

Histopathological examination of the surgical specimen revealed an encapsulated tumoral mass measuring $21 \times 15 \times 9 \mathrm{~cm}$, weighting $1628 \mathrm{~g}$, with extensive areas of necrosis and hemorrhage. The adrenal gland, ureter or renal vein were not involved, and the lymph node analysis was negative for neoplasia. Patient has been followed for 1 year with no signs of recurrence.

\section{DISCUSSION}

Primary synovial sarcoma of the kidney is a type of renal sarcoma. Leiomyosarcoma represents $40-60 \%$ of the described renal sarcomas, followed by rhabdomyosarcoma, histiosarcoma, chondrosarcoma and osteosarcoma, liposarcoma, angiosarcoma and hemangiopericytoma (1-3). Only 20 cases were reported in the literature. It affects young individuals, of both genders, between 20 and 50 years, presenting a clinical picture that is similar to renal tumors in general (1). There is no clinical or imaging characteristic that can indicate the diagnosis (1-5). Differential diagnosis with other renal tumors constituted by spindle or round cells is difficult, requiring immunohistochemical studies or molecular analysis. Among the differential diagnoses, are especially the mesoblastic nephroma and adult neuroectodermal tumor (PNET), in addition to adult Wilms' tumor and fibrosarcoma.

The mesoblastic nephroma is usually immunoreactive for actin and negative for epithelial markers. The synovial sarcoma presents immunoreaction for epithelial markers such as cytokeratin and epithelial membrane antigen, generally with focal distribution. The proteins CD99 and Bcl-2 were detected in $70 \%$ and $100 \%$ of cases, respectively. PNET tumors are immunoreactive to CD99 and generally negative for Bcl-2 and epithelial membrane antigen. However, since there is not a specific immunohistochemical marker for the synovial sarcoma, definitive diagno- 

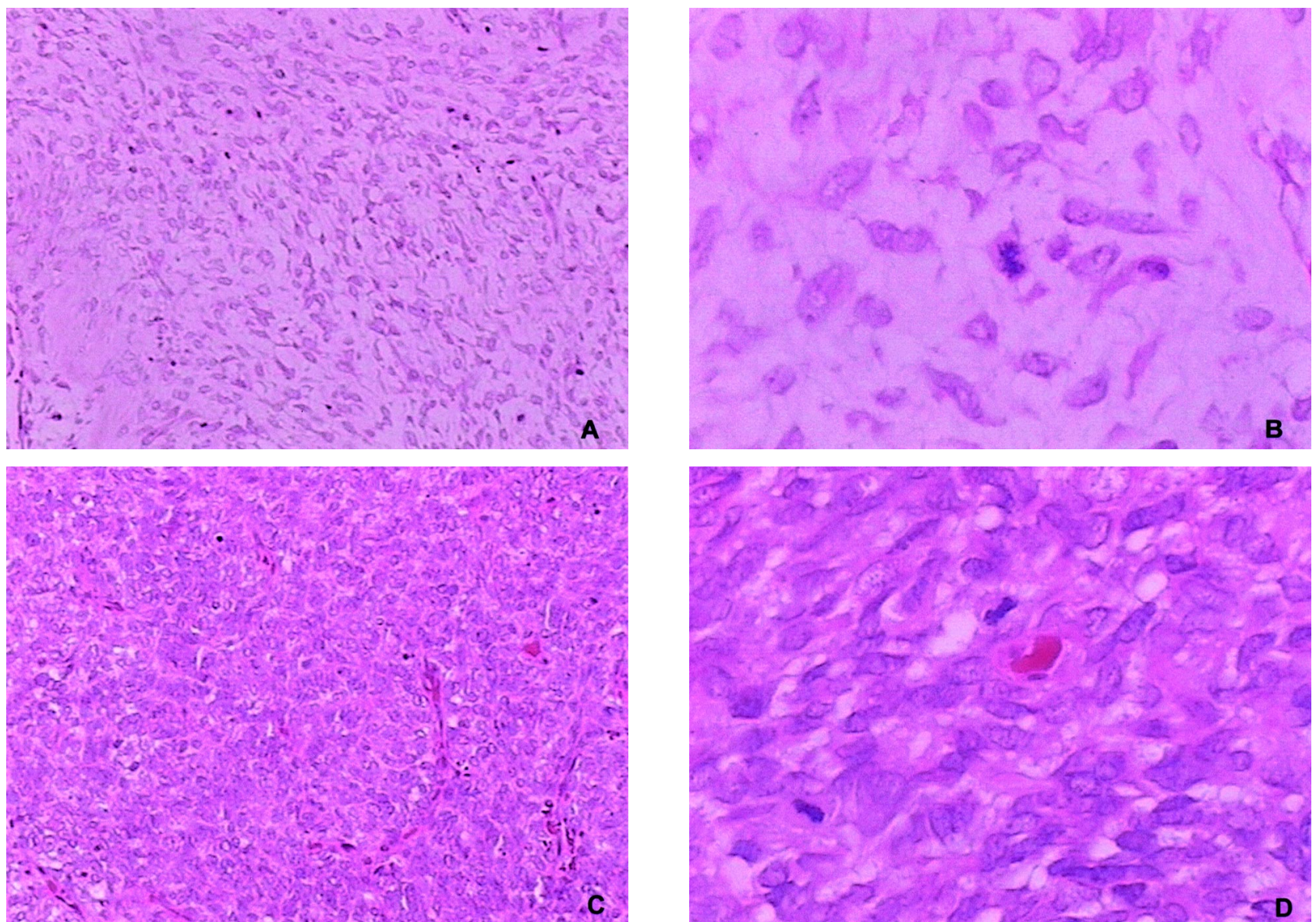

Figure 3 - Histology of incision biopsy showing a spindle cell component (monophasic fibrous) (A and B), and small round cells component (poorly differentiated) (C and D) (HE, A and C, X33; B and D, X132).
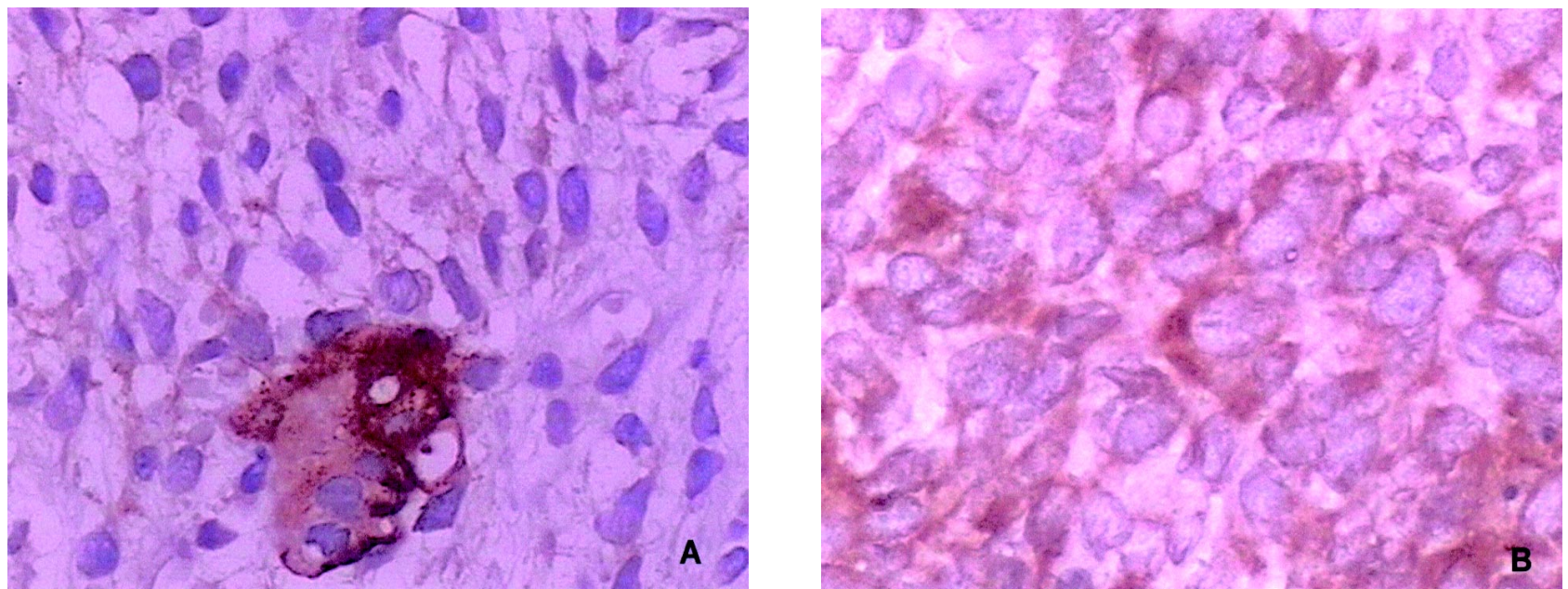

Figure 4 - Immunohistochemical study. A) - Immunoreactivity of the monophasic fibrous component to epithelial membrane antigen around imprisoned renal tubule. B) - Positivity of the poorly differentiated component to Bcl-2 (Immunolabeling, X132). 
sis can be achieved only by identifying the characteristic $\mathrm{T}$ chromosomal translocation $(\mathrm{X} ; 18)$, through reverse transcriptase polymerase chain reaction with fluorescence in situ hybridization (FISH) (1-3). In the present case, since we could not count on chromosomal analysis, diagnosis was established based on conventional morphologic microscopic analysis and immunohistochemistry.

In one research on 17 cases (1), 4 presented lung, liver or bone metastases and evolved to death, 2 presented pelvic recurrence.

Adjuvant and neoadjuvant chemotherapy, using high doses of doxorubicin, cisplatin and iphosphamide $\left(14 \mathrm{~g} / \mathrm{m}^{2}\right)$ performed in 14 patients without initial metastatic disease, rendered $93 \%$ of patients disease-free in a mean follow-up of 37 months (6 to 85 months) (5).

The base for chemotherapy in such cases is the iphosphamide, usually reducing the tumor volume by $50 \%$ or more $(3,5)$. There is no consensus in the literature concerning the standard chemotherapy scheme. In this case, the scheme consisting in iphosphamide and adriamycin reduced approximately $50 \%$ of the tumor, enabling its surgical resection.

\section{REFERENCES}

1. Argani P, Faria PA, Epstein JI, Reuter VE, Pearlman EJ, Beckwith JB, et al.: Primary renal synovial sarcoma. Am J Surg Pathol. 2000; 24: 1087-96.

2. Bella AJ, Winquist EW, Pearlman EJ: Primary synovial sarcoma of the kidney diagnosed by molecular detection of SYT-SSX fusion transcripts. J Urol. 2002; 168: 1092-3.

3. Koyama S, Morimitsu Y, Morokuma F, Hashimoto H: Primary synovial sarcoma of the kidney: report of a case confirmed by molecular detection of the SYTSSX2 fusion transcripts. Pathol Int. 2001; 51: 385-91.

4. Kim DH, Sohn JH, Lee Mc, Lee G, Yoon GS, Hashimoto H, et al.: Primary synovial sarcoma of the kidney. Am J Surg Pathol. 2000; 24: 1097-104.

5. Kampe CE, Rosen G, Eilber F, Eckardt J, Lowenbraun S, Foster J, et al.: Synovial sarcoma. A study of intensive chemotherapy in 14 patients with localized disease. Cancer. 1993; 72: 2161-9.

Received: October 2, 2003

Accepted after revision: January 9, 2004

Correspondence address:

Dr. Carlos Hermann Schaal

Rua Luís Paiva, 100

Jaú, SP, 17210-180, Brazil

Fax: + 5514 3624-5155

E-mail: schaal.jau@uol.com.br 